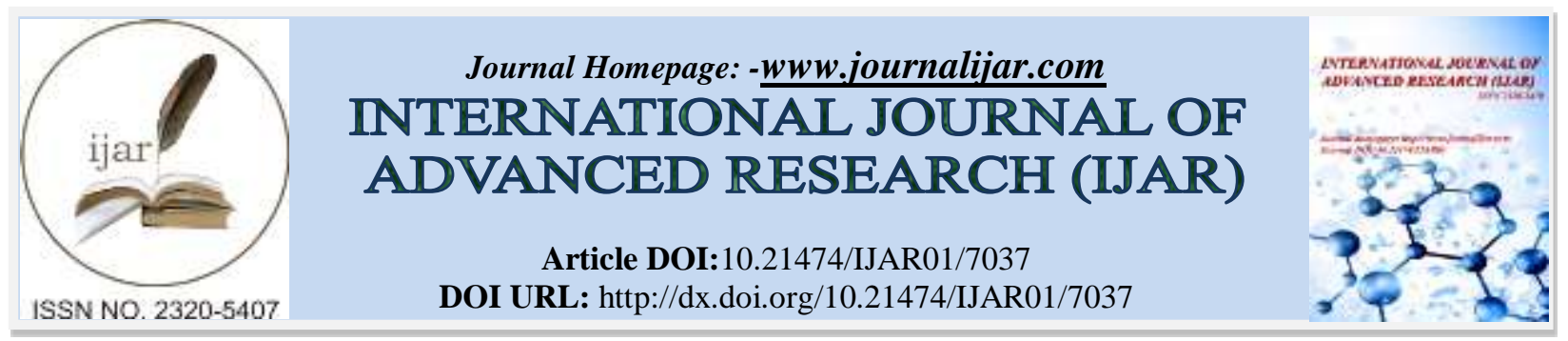

RESEARCH ARTICLE

\title{
LEVEL OF KNOWLEDGE AND ATTITUDE TOWARDS THE USE OF FILLERS.
}

Heba Abdulahad Alturkistany ${ }^{1}$, Majidah Saleh Alshammari ${ }^{2}$ and Mohammed Saleh Qari ${ }^{3}$.

1. Family medicine resident, King Fahad Armed Forces Hospital, Jeddah, Saudi Arabia.

2. General practitioner, Jeddah, Saudi Arabia.

3. Consultant dermatologist, Department of dermatology, Faculty of medicine, King Abdulaziz University Hospital.

\section{Manuscript Info}

Manuscript History

Received: 05 March 2018

Final Accepted: 07 April 2018

Published: May 2018

Keywords:-

Dermatology, cosmetics, fillers, injections.

\section{Abstract}

Objective: to assess the knowledge and attitude of females in Saudi Arabia towards the use of filler injections, and to explore the factors that influence their decision to have it.

Study design: cross-sectional study.

Subjects and Methods: online self-administered questionnaire was distributed randomly to 204 Saudi Arabian females from November 2016 to January 2017.

Descriptive analysis was done for all the data to obtain the required frequencies and percentages.

Results: results showed that $(96.6 \%)$ know about fillers and only $(3.4 \%)$ never heard about it. The most recognized injection areas were the lips $(86.8 \%)$, cheeks $(73 \%)$, and nasolabial lines $(70.1 \%)$.

The most recognized side effects were bruising $(64.2 \%)$, numbness $(61.8 \%)$ and over-correction $(55.4 \%)$.

Further analysis showed that $(16.7 \%)$ of those are in fact users of fillers, and they received it in a medical setting by (90.6\%), while $(9.4 \%)$ received it in non-medical setting such as beauty salons.

Among the study sample, the most important factors that influenced the decision to have fillers were doctors and family opinion equally by (43.8\%).

Conclusion: a good level of awareness was found but our society needs further education about fillers, especially regarding the aesthetic outcome in order to meet patient expectations and improve the overall experience. Further studies to evaluate the practice of filler injections are advisable.

Copy Right, IJAR, 2018,. All rights reserved.

\section{Introduction:-}

Filler injections are the second most commonly performed cosmetic procedure after botulinum toxin injections ${ }^{(1)}$. The number of patients seeking fillers had become larger and it became widely popular in Saudi Arabia during the last few years. This growing interest in fillers occurred mainly because of the ability to accomplish aesthetically pleasing results and return to daily activities quickly in contrast to invasive surgery. 
Fillers are used to achieve a youthful face and they are injected to replace the volume that is lost in the cheeks, enhance the lips, define the contour of the nose and chin, and smooth lines in the nasolabial folds ${ }^{(2)}$. There are many filling agents but the predominant type is synthetic Hyaluronic-acid. It is a glycosaminoglycan found naturally in the dermis which helps provide skin turgor. It is absorbed and eliminated by the lymphatic system then the liver ${ }^{(3,4)}$.

Adverse events are rare but like any cosmetic procedure it can result in complications, they include: erythema, swelling, ecchymosis, infection, allergic reaction, granuloma formation, and the most serious is necrosis. They are related to injection technique, volume and sterility, and can be managed medically or surgically ${ }^{(5)}$.

Many of the patients are not being educated before the procedure, which can lead to dissatisfaction and a lack of awareness. A study was done in Riyadh, Saudi Arabia, it included 47 patients and half of them were not aware of the injected material as they had it done by unlicensed practitioners ${ }^{(6)}$. This emphasizes the importance of increasing the level of awareness.

To our knowledge, there are limited studies in Saudi Arabia. One study was done in Riyadh to assess knowledge and attitude towards fillers and botulinum toxin injections but among dentists ${ }^{(7)}$ and no similar study had been conducted among patients. The aim of the study is to assess the knowledge and attitude of females in Saudi Arabia towards the use of filler injections, and to explore the factors that influence their decision to have it.

\section{Methods:-}

This was a cross-sectional study conducted during a time period of two months, from November 2016 to January 2017. An online self-administered questionnaire was distributed randomly to 204 Saudi Arabian females of all age groups. There were no exclusion criteria.

The data was collected using a data collection spreadsheet, including demographic information such as age, educational level and martial status.

Regarding knowledge assessment, the questionnaire contained questions about filler material types, areas of injection, and side effects.

There were also questions on whether they received fillers or not, and it focused on the most important factors to them that influenced their decision to have fillers such as family, friends or doctor's recommendations and social media.

The data was coded and entered into Statistical Package for Social Sciences (SPSS version 21.0) Descriptive analysis was done to obtain the required frequencies and percentages.

\section{Results:-}

A total of 204 Saudi Arabian females were included in our study. The demographic features of the population are shown in (Table 1).

\section{Knowledge about fillers:-}

Most of our participants knew about filler injections (96.6\%) and only (3.4\%) never heard about it. The majority reported that they knew there is more than one type of filler $(76.0 \%)$.

The most recognized injection areas were in the following order, lips $(86.8 \%)$, cheeks $(73 \%)$, nasolabial lines (70.1\%), filling wrinkles (68.6\%), nose and chin contouring (53.9\%). Results regarding the frequency are shown in (Figure 1).

When asked about the side effects, more than half (64.2\%) recognized bruising, followed by numbness (61.8\%), over-correction (55.4\%), and infection (48.5\%).

As shown in (Table 2), the majority of our participants had chosen plastic surgeons (85.8\%) and dermatologists $(61.3 \%)$ when asked about who is qualified to inject fillers. 


\section{Attitude towards fillers:-}

A number of (16.7\%) are in fact users of fillers, and they had received it in a medical setting by (90.6\%), while $(9.4 \%)$ received it in non-medical setting such as beauty salons.

The most important factors that influenced their decision to have fillers: doctors and family opinion equally by $(43.8 \%)$, then friends' opinion $(31.3 \%)$, and social media $(25.0 \%)$.

Finally, they reported that having fillers made them feel better about themselves by (68.8\%) and they would have dermal fillers again $(87.5 \%)$.

Table 1:-Demographic features of participants

\begin{tabular}{|c|c|c|c|}
\hline & Features & Number & Percentage $\%$ \\
\hline \multirow[t]{4}{*}{ Age } & 24 or less & 82 & 40.2 \\
\hline & $25-34$ & 88 & 43.1 \\
\hline & $35-44$ & 16 & 7.8 \\
\hline & 45 or over & 18 & 8.8 \\
\hline \multirow[t]{3}{*}{ Level of education } & Postgraduate & 37 & 18.1 \\
\hline & Collage & 153 & 75.0 \\
\hline & High school or less & 14 & 6.9 \\
\hline \multirow[t]{4}{*}{ Marital Status } & Married & 75 & 36.8 \\
\hline & Single & 119 & 58.3 \\
\hline & Divorced & 7 & 3.4 \\
\hline & Widow & 3 & 1.5 \\
\hline
\end{tabular}

Figure 1:-Areas of filler injections

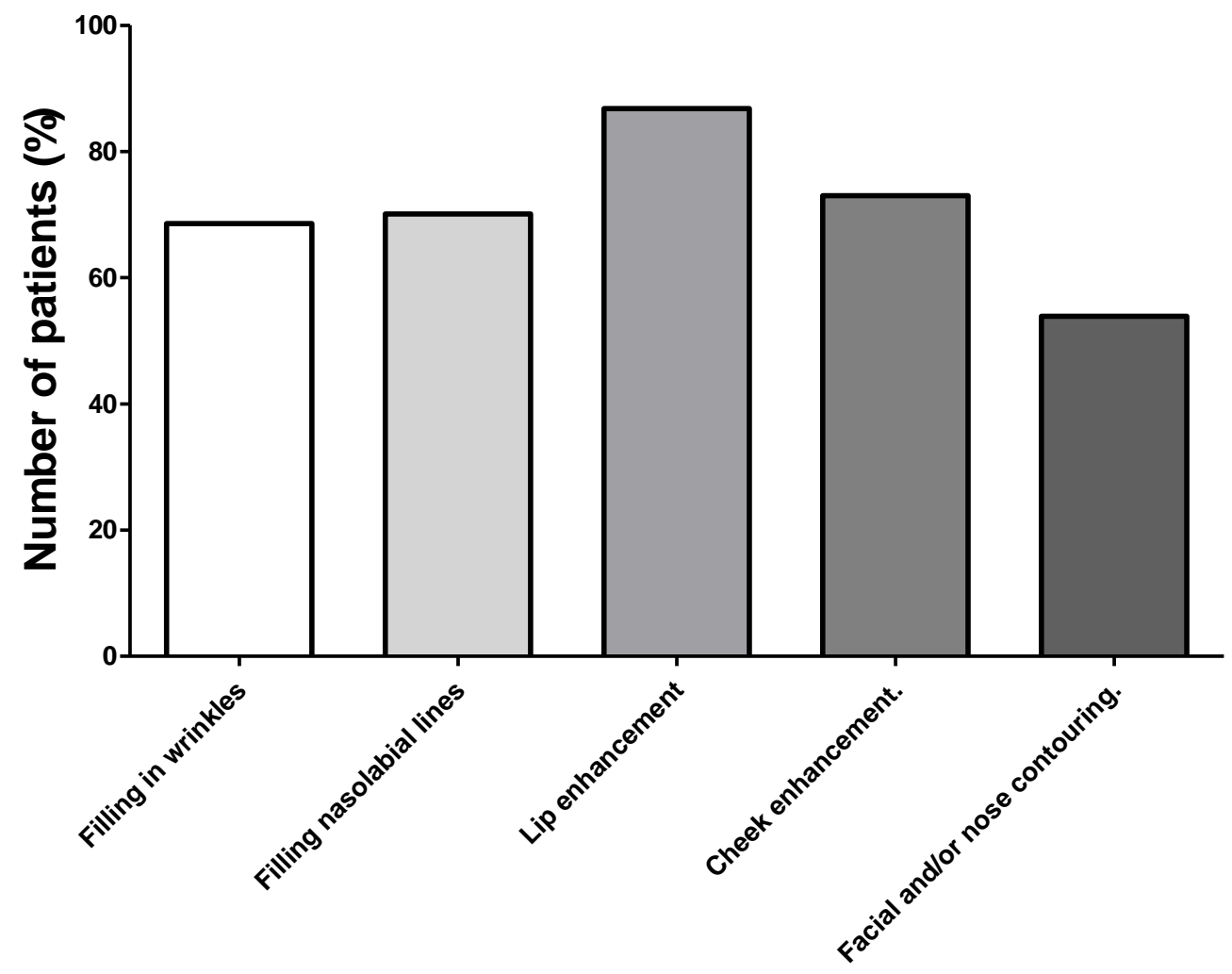

Table 2:-Who is qualified to inject fillers

\begin{tabular}{|l|c|c|}
\hline Occupation & Number & Percentage \% \\
\hline Plastic surgeon & 175 & 85.5 \\
\hline Dermatologist & 125 & 61.3 \\
\hline
\end{tabular}




\begin{tabular}{|l|l|l|}
\hline General Physician & 7 & 3.4 \\
\hline Nurse & 4 & 2.0 \\
\hline Salon/spa personnel & 4 & 2.0 \\
\hline
\end{tabular}

\section{Discussion:-}

Up to the researchers' knowledge and after literature reviews, no similar study had been conducted among patients in Saudi Arabia to assess the level of knowledge and attitude towards the use of fillers. However, one similar study was conducted among dentists in the city of Riyadh, and it showed that the dentists had good knowledge about fillers.

In our cross sectional study, we found that (96.6\%) of patients knew about fillers and they had demonstrated a good level of knowledge regarding fillers, its uses, and its side effects.

Most of the filler users had it injected in a medical setting (90.6\%), and when they considered fillers they took into consideration their doctor's advice and family's opinion equally as an important factor to them by (43.8\%), which shows that they were well informed.

\section{Conclusion and recommendations:-}

In conclusion, a high level of awareness was found among participants, especially with the increasing popularity of fillers in the cosmetic field in Saudi Arabia. Due to this high-demand, the physicians should aim to educate and inform their patients regarding aesthetic outcomes and expectations, in order to improve the overall experience. A major limitation of this study is the small sample size.

Further studies to evaluate the practice of filler injections are advisable.

\section{Websites:-}

1. American Society of Plastics Surgeons.2015 Plastic Surgery Statistics Report. Retrieved from: https://d2wirczt3b6wjm.cloudfront.net/News/Statistics/2015/plastic-surgery-statistics-full-report-2015.pdf

\section{Journal References:}

2. Vedamurthy M, Vedamurthy A. Dermal fillers: tips to achieve successful outcomes. Journal of Cutaneous and Aesthetic Surgery. 2008 Jul-Dec; 1(2): 64-67.

3. Ballin A.C, Brandt F. S, Cazzaniga A. Dermal Fillers: An Update. American Journal of Clinical Dermatology. Aug 2015; 16(4): 271-283.

4. Klein A.W, Elson, M.L. The history of substances for soft tissue augmentation. Journal of Dermatologic Surgery. Dec 2000 ; 26(12): 1096-1105.

5. De Boulle K, Heydenrych I. Patient factors influencing dermal filler complications: prevention, assessment, and treatment. Clinical, Cosmetic and Investigational Dermatology. Apr 2015; 8: 205-214.

6. Salati S.A, Al Aithan B. Complications of dermal fillers - an experience from Middle-East. Journal of Pakistan Association of Dermatologists. 2012; 22(1): 12-18.

7. Al Hamdan E. M, Algheryafi A. M, Al-Ghareeb F. J, Ashri N. Y. Knowledge and attitude of dentists towards the use of botulinum toxin and dermal fillers in dentistry, Riyadh, Saudi Arabia. Journal of Cosmetic and Laser Therapy. 2013 15(1): 46-54. 